\title{
Technical note: Method for isolation of the bovine sweat gland and conditions for in vitro culture
}

\author{
S. Hamzaoui, ${ }^{\star 1}$ C. A. Burger, $\dagger^{2}$ J. L. Collier, $\dagger$ and R. J. Collier ${ }^{3}$ \\ *Grup de Recerca en Remugants, Departament de Ciència Animal i dels Aliments, Universitat Autònoma de Barcelona, Bellaterra 8193, Spain \\ †School of Animal and Comparative Biomedical Science, University of Arizona, Tucson 85719
}

\begin{abstract}
Apocrine sweat glands in bovine skin are involved in thermoregulation. Human, horse, and sheep sweat gland epithelial cells have been isolated and grown in vitro. The present study was conducted to identify a method to isolate bovine sweat glands and culture apocrine bovine sweat gland epithelial cells in vitro. Mechanical shearing, collagenase digestion, centrifugation, and neutral red staining were used to identify and isolate the apocrine glands from skin. Bovine sweat glands in situ and after isolation comprised 2 major cell types consisting of a single layer of cuboidal epithelial cells resting on a layer of myoepithelial cells. In situ, the glands were embedded in a collagen matrix primarily comprising fibroblasts, and some of these cells were also present in the isolated material. The isolated material was transferred to complete medium (keratinocyte serum-free medium, bovine pituitary extract, and human recombinant epidermal growth factor $+2.5 \%$ fetal bovine serum) in a T 25 flask (Falcon, Franklin Lakes, NJ) with media film and then incubated at $37^{\circ} \mathrm{C}$ for $24 \mathrm{~h}$. After sweat glands adhered to the bottom of the flask, an additional $2 \mathrm{~mL}$ of complete medium was added and the medium was changed every $3 \mathrm{~d}$. Isolated apocrine sweat glands and bovine sweat gland epithelial cells were immunostained for cytokeratin and fibroblast specific protein, indicating fibroblast-free cultures.
\end{abstract}

Key words: apocrine sweat gland, bovine, isolation

\section{Technical Note}

The mammalian sweat gland is known to be involved in secretion, excretion, and thermoregulation (Saga, 2002). Research into the role of the apocrine sweat

\footnotetext{
Received October 26, 2017.

Accepted January 15, 2018.

${ }^{1}$ Current address: Department of Agronomic Science, Faculty of Nature, Life Science and Earth Science, Bouira University, Road DRISSI Yahya, 10000 Bouira, Algeria.

${ }^{2}$ Current address: Department of Molecular and Cellular Biology, Baylor College of Medicine, Houston, TX 77030.

${ }^{3}$ Corresponding author: rcollier@ag.arizona.edu
}

glands of cattle in heat regulation has been undertaken by various investigators (Yamane and Ono, 1936; Brody, 1945; Findlay, 1950; Findlay and Yang, 1950). Although apocrine glands contribute little to thermal cooling in humans, they are the only effective sweat glands in hoofed animals such as the donkey, cow, horse, and camel (Bullard et al., 1970). Evaporation becomes the major route of heat loss as ambient temperature approaches core body temperature because it works on a vapor pressure gradient rather than a temperature gradient (Collier and Gebremedhin, 2015), and about 70 to 85 percent of maximal heat loss via evaporation occurs through the skin above the thermoneutral zone in cattle (Finch, 1986). Animal factors that affect the efficiency of cutaneous evaporative heat loss include hair coat density and thickness, hair length and color, skin color, and density of sweat glands (Klungland and Vage, 2003; Olson et al., 2003). Cattle with shorter hair that is greater in diameter and lighter in color are better adapted to heat stress than cattle with longer, darker hair (Bertipaglia et al., 2007). This was believed to be due to the fact that evaporation rate is greater from skin in cattle with short hair (Bertipaglia et al., 2007). This was confirmed by Dikmen et al. (2008).

The isolation and culture of sweat gland epithelial cells can provide powerful tools for studying the structure and function of sweat glands at the cellular level. However, the isolation and culture of sweat gland epithelial cells is very time consuming (Hongpaisan et al., 1996; Lei et al., 2008), and there is currently no published method for isolation of the bovine apocrine sweat gland. Because the isolation of bovine sweat gland epithelial cells has never been reported, the current study was conducted to identify a method to isolate bovine sweat glands and culture apocrine bovine sweat gland epithelial cells in vitro. Brayden and Fitzpatrick (1995) demonstrated that human eccrine sweat glands take up neutral red, which can be used as a marker to identify sweat glands during isolation. Based on the traditional method of isolation and culture of human sweat gland epithelial cells, Mörk et al. (1995) modified and improved later by Tao et al. (2010), we developed a new method for the isolation of bovine 
apocrine sweat glands. We hypothesized that we could modify techniques used to isolate eccrine sweat glands from humans and apocrine sweat glands from horse and sheep skin to isolate the sweat gland of the bovine.

All procedures used in this study were conducted under a protocol approved by the University of Arizona Animal Care and Use Committee. Sweat glands were isolated from the skin of udders taken from cattle processed at the University of Arizona abattoir. Full-thickness noncauterized skin samples were taken from fresh healthy cow udders from slaughter at the University of Arizona Food Products and Safety Lab (Tucson) to the research laboratory within $15 \mathrm{~min}$ while stored on ice. The skin was sprayed with $70 \%$ ethanol followed by betadine for sterilization and was shaved using an electric razor, followed by a disposable razor to remove as much hair as possible. Using a scalpel, an 8 -cm $\times 8$-cm square was cut from the udder and as much fat was removed as possible. Media and other solutions were routinely prepared by a volume/ volume ratio unless otherwise stated. The tissue was added to a 50-mL conical centrifuge tube (Corning Inc., Corning, New York) that contained $10 \mathrm{~mL}$ of PBS with $0.1 \%$ gentamicin and $0.1 \%$ solution of penicillin $(10,000$ units) and streptomycin (10 mg/mL; Sigma-Aldrich, St. Louis, MO). Sections of the $8-\mathrm{cm} \times 8-\mathrm{cm}$ square were additionally cut into smaller pieces in a sterile hood and were transferred into a preweighed Petri dish containing wash medium comprising $10 \mathrm{~mL}$ of sterile M199 (Sigma-Aldrich), 0.1\% gentamicin, and 0.1\% antibiotic/antimycotic (Sigma-Aldrich). The tissue weight was recorded so that $1 \mathrm{~g}$ of tissue was in $10 \mathrm{~mL}$ of medium. The skin was thinly sliced, in a serial manner, using a Stadie-Riggs hand microtome (Thomas Scientific, Swedesboro, NJ) and was immediately returned to the Petri dish.

Once all skin samples $(\sim 5 \mathrm{~g})$ were thinly sliced, the tissue was placed on a sterile cutting board and wetted with medium in a sterile hood. Using standard singleedge razor blades, the tissue was minced to the consistency of applesauce for no longer than $10 \mathrm{~min}$ and then returned to the wash medium. This medium with tissue was added to a $250-\mathrm{mL}$ fluted flask that contained the daytime digestion medium: $0.2 \%(\mathrm{wt} / \mathrm{vol})$ type II collagenase (Worthington, Lakewood, NJ), an adaptation from Collier et al. (2006), medium M199 with 0.1\% antibiotic/antimycotic and 5\% FBS (Sigma-Aldrich), 5\% (wt/vol) neutral red (Sigma-Aldrich), a modification from Brayden and Fitzpatrick (1995), and the $10 \mathrm{~mL}$ of wash medium with minced skin, for a total of $50 \mathrm{~mL}$. The flask was placed in a $37^{\circ} \mathrm{C}$ shaking incubator at 175 rpm for $60 \mathrm{~min}$. The digested material was transferred to a $50-\mathrm{mL}$ conical centrifuge tube (Corning Inc.) and was centrifuged at $400 \times g$ for 4 min. The remaining pellet was placed into a tissue culture-treated $\mathrm{T} 75$ flask (Corning Inc.) containing $15 \mathrm{~mL}$ of M199 with $0.1 \%$ gentamicin, $0.1 \%$ antibiotic/antimycotic, $0.02 \%$ collagenase, and 1\% FBS (overnight digestion media) for 20 to $24 \mathrm{~h}$ in an incubator at $37^{\circ} \mathrm{C}$ and $5 \% \mathrm{CO}_{2}$.

After 20 to $24 \mathrm{~h}$, the digested skin was transferred to a Petri dish (Corning Inc.), which was placed on ice. A dissecting microscope sitting in a sterile hood was used to separate the sweat glands from skin and hair follicles. A micropipette was used to transfer isolated sweat glands, stained red, to a Petri dish filled with $10 \mathrm{~mL}$ of keratinocyte medium (Gibco, Waltham, MA) completed with $2.5 \%$ FBS, $0.1 \%$ gentamicin, and $0.1 \%$ antibiotic/antimycotic, stored on ice during collection (Figure 1). As shown in Figure 1, the sweat glands are easily identified because they selectively take up the neutral red stain. Any concentration of neutral red or collagenase greater than $5 \%$ resulted in no cell growth. The isolated sweat glands were transferred from the Petri dish to a $15-\mathrm{mL}$ conical centrifuge tube (GeneMate, Kayesville, UT) and spun at $400 \times g$ for $4 \mathrm{~min}$, and the medium was decanted. To separate the epithelial cells from the fibroblasts, the cultures were digested with trypsin for 2 min at $37^{\circ} \mathrm{C}$. Fibroblasts were then washed away and epithelial cells remained in the flask. The trypsinization of epithelial cells was then performed (Freshney, 2010). Trypsin solution was decanted, and $1 \mathrm{~mL}$ of keratinocyte medium was added to resuspend the glands. The medium and glands were added to the floor of the T 25flask (Falcon) that was prewetted with $1 \mathrm{~mL}$ of keratinocyte medium or a 24-well plate (Corning Inc.) that had been prewetted for culturing or had a collagen gel matrix as reported by Hernandez et al. (2008). Glands were dispersed as broadly as possible, and the culture dish was then placed in an incubator at $37^{\circ} \mathrm{C}$ and $5 \% \mathrm{CO}_{2}$. The glands were allowed to attach to the dish for 24 to $48 \mathrm{~h}$ before $2 \mathrm{~mL}$ of medium was added to the $\mathrm{T} 25$ flask.

The 24-well plate cultures contained about 7 to 10 glands per well that had been prewetted with $50 \mathrm{uL}$ of keratinocyte medium or was collagen coated. The 24-well plate was also placed in a $37^{\circ} \mathrm{C}$ and $5 \% \mathrm{CO}_{2}$ incubator. The glands were allowed to attach to the dish for 24 to $48 \mathrm{~h}$ before $250 \mathrm{uL}$ of medium was added to each well.

Isolated sweat glands and the cells that grew from them were grown in keratinocyte medium with $2.5 \%$ FBS as reported by Tao et al. (2010). This medium consisted of keratinocyte medium (Gibco), 2.5\% FBS (Sigma-Aldrich), $50 \mu \mathrm{g} / \mathrm{mL}$ bovine pituitary extract (bPE; Gibco), $5 \mathrm{ng} / \mathrm{mL}$ of human epidermal growth factor (hEGF; Gibco), $0.1 \%$ gentamicin, and $0.1 \%$ antibiotic/antimycotic and is further referred to as complete keratinocyte medium. For the isolated sweat 
glands, the medium was changed every 48 to $72 \mathrm{~h}$. The $\mathrm{T} 25$ flasks contained $5 \mathrm{~mL}$ of complete medium, and the 24-well plates contained $450 \mathrm{uL}$ of medium in each well. After about $5 \mathrm{~d}$, cells began to appear; the complete medium was changed every 48 to $72 \mathrm{~h}$. Once the cells were 70 to $80 \%$ confluent, they were passaged into a T 25 flask or a T 75 flask.

The epithelium and bovine myofibroblasts were treated the same way in cell culture. Medium was changed every 2 to $3 \mathrm{~d}$. Once the cells were 70 to $80 \%$ confluent, they were passaged into a new flask to continue growing, were moved to 12 -well plates (Corning Inc.) or coverslips for staining, or were put into $1 \mathrm{~mL}$ of TRIzol (Invitrogen, Carlsbad, CA) for RNA isolation.

A medium test, modified from Gomm et al. (1997), was performed to try to separate the 2 cell types from one another. In addition to the complete medium, we made a myoepithelium medium and an epithelium medium. The myoepithelium medium contained keratinocyte medium with $5 \mu \mathrm{g} / \mathrm{mL}$ of insulin, $0.5 \mu \mathrm{g} / \mathrm{mL}$ of hydrocortisone, $5 \mathrm{ng} / \mathrm{mL}$ of hEGF, $0.05 \mathrm{mg} / \mathrm{mL}$ of bPE, and no FBS. The epithelium medium contained keratinocyte medium with $5 \mu \mathrm{g} / \mathrm{mL}$ of insulin, $1 \mu \mathrm{g} /$ $\mathrm{mL}$ of hydrocortisone, $5 \mathrm{ng} / \mathrm{mL}$ of hEGF, no bPE, and $5 \%$ FBS. The medium was changed every 2 to $3 \mathrm{~d}$.

Fetal sheep fibroblasts were maintained in M199 with $10 \%$ FBS, $0.1 \%$ gentamicin, and $0.1 \%$ antibiotic/antimycotic. Once the cells were 70 to $80 \%$ confluent, they were either passaged into a new flask to continue growing or moved to 12-well plates or coverslips for staining.

Epithelia, bovine myofibroblasts, or fetal sheep fibroblasts used for staining were passaged into a 6-well plate (MidSci, Valley Park, MO) that contained

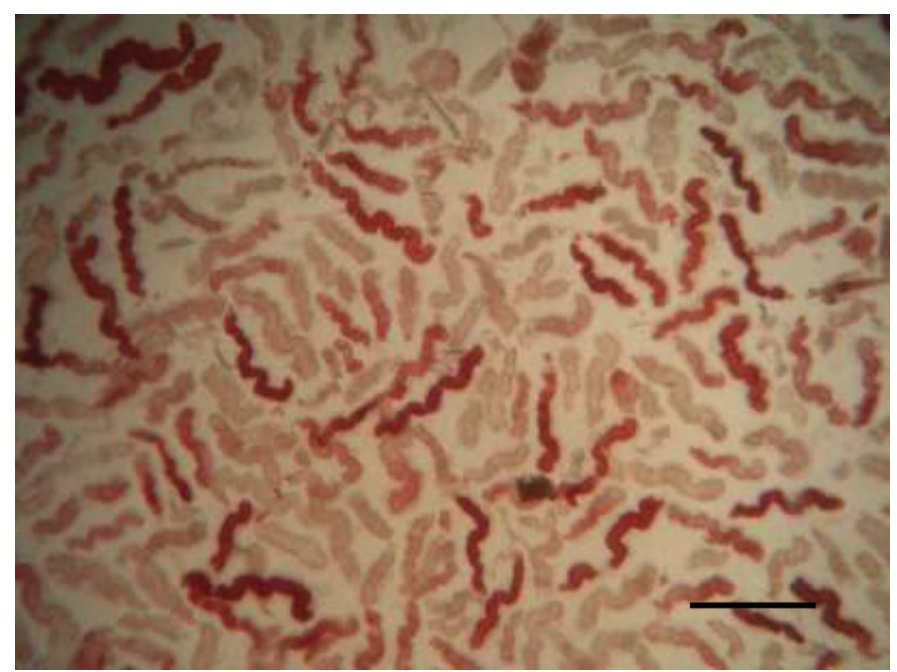

Figure 1. Isolated bovine apocrine sweat glands stained with neutral red. Bar represents $10 \mu \mathrm{m}$. collagen-coated coverslips that received 500,000 cells in $2 \mathrm{~mL}$ of medium/well. The medium was changed every 48 to $72 \mathrm{~h}$ until 70 to $80 \%$ confluent.

The skin from a bovine udder and isolated apocrine sweat glands was obtained and flash frozen by embedding the tissue with optimum cutting tissue (Tissue Tek, Torrance, CA), submerging it in cold 2-methylbutane and allowing it to freeze for $10 \mathrm{~s}$, and then transferring it to $-80^{\circ} \mathrm{C}$. Tissue sections $(8 \mu \mathrm{m}$ thick $)$ were cut with a Microm HM 520 cryostat (GMI, Ramsey, MN) for immunostaining, adapted from Cole et al. (2009). Slides were fixed in 2\% paraformaldehyde (Sigma-Aldrich), washed with $1 \times$ PBS 3 times, and then blocked with $10 \%$ FBS with $1 \%$ triton X-100 (Sigma-Aldrich) in PBS for $1 \mathrm{~h}$ in a humidified chamber. The block was removed, and the tissue samples were incubated in primary antibody overnight at $4^{\circ} \mathrm{C}$. The primary antibodies used were anti- $\beta$-actin monoclonal mouse antibody (1:700; Sigma-Aldrich) and anti-CK 4 goat polyclonal antibody (1:100; Santa Cruz Biotechnology, Dallas, TX).

After $24 \mathrm{~h}$, the primary antibody was removed and the slides were washed 3 times with $1 \times$ PBS, $0.2 \%$ tween-20 (Abcam, Cambridge, MA). The tissue was incubated in the secondary antibody diluted 1:1,000 in $1 \%$ FBS for $1 \mathrm{~h}$ at room temperature, protected from the light. The secondary antibodies were all Alexa Fluor; for anti- $\beta$-actin antibody the secondary antibody was donkey anti-mouse 594 (Invitrogen), and for CK4 the secondary antibody was donkey anti-goat 488 (Invitrogen). The secondary antibody was removed, and the slides were washed 3 times with $1 \times$ PBS, $0.2 \%$ tween-20 and 2 times with water and then incubated in 4',6-diamidino-2-phenylindole (1:1,000; Sigma-Aldrich) for 2 min. 4',6-Diamidino-2-phenylindole was removed and the slides were washed twice with water and then mounted in $50 \%$ glycerol with $10 \mathrm{~m} M$ Tris- $\mathrm{HCl}$, pH 8 (Life Technologies, Carlsbad, CA). Fluorescent images were visualized on a Leica DM5500 (Buffalo Grove, IL) microscope system and digitally captured with a Spot Pursuit 4 Megapixel CCD camera (Diagnostic Instruments Inc., Sterling Heights, MI). An appropriate pseudocolor for each wavelength was applied to images using the ImageJ program (National Institutes of Health, Bethesda, MD).

Enough glands were separated from the skin so that each well of a 24-well plate had 7 to 10 apocrine sweat glands; at least 100 or more remaining glands were added to TRIzol for RNA extraction. Adherence of the sweat glands to the plate occurred within $24 \mathrm{~h}$, with cell growth occurring 3 to $5 \mathrm{~d}$ after plating.

Immunofluorescent staining using $\beta$-actin and CK4 of bovine udder whole skin and isolated apocrine sweat glands revealed 2 layers of cells in situ that were still 
A

\section{B}

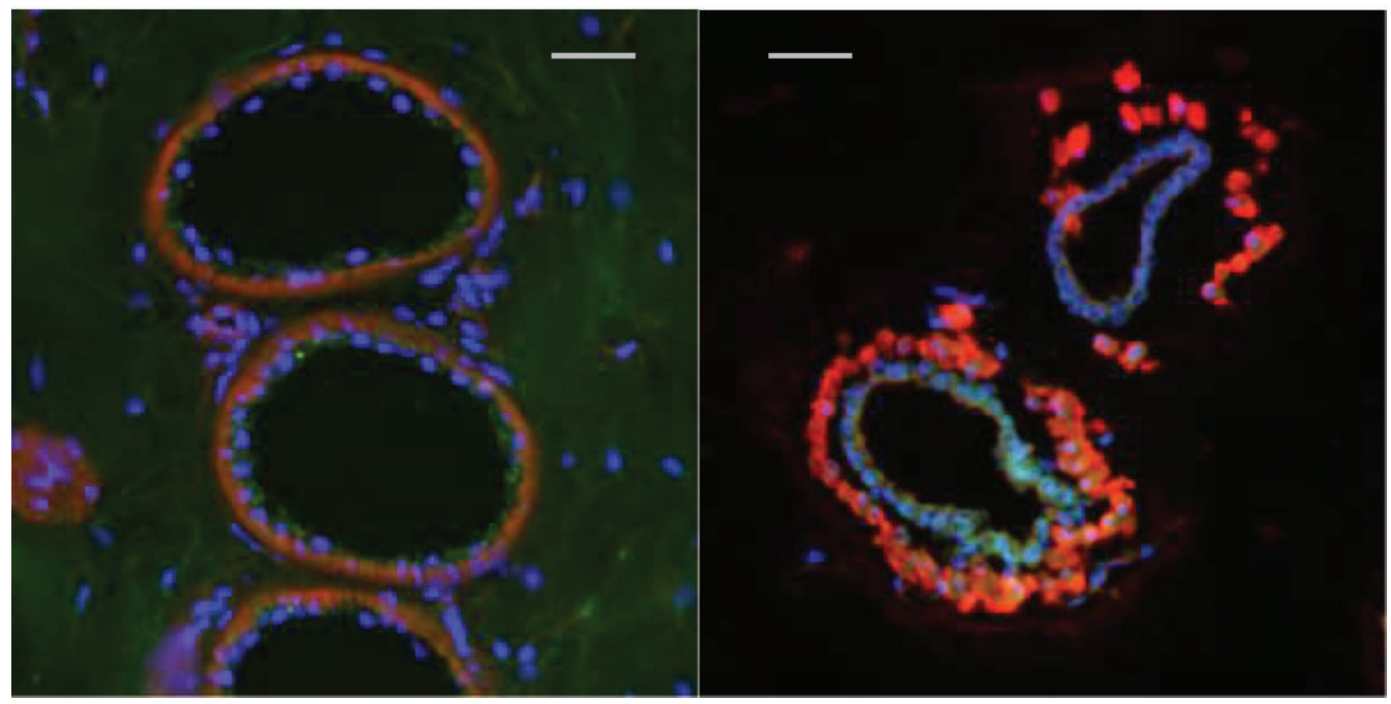

Figure 2. Immunofluorescent staining of bovine udder whole skin and isolated sweat gland cross-sections. There are 2 layers of cells present in sweat glands in situ and when individual glands are isolated. Bar represents $40 \mu \mathrm{m}$. (A) Cross-section of apocrine sweat glands in whole skin. (B) Cross-section of isolated apocrine sweat gland. Red is $\beta$-actin, green is cytokeratin 4, and blue is 4 ',6-diamidino-2-phenylindole.

present when sweat glands were isolated from whole skin (Figures $2 \mathrm{~A}$ and $\mathrm{B}$ ). The first layer comprised a single layer of cuboidal epithelium resting on a second layer of myoepithelial cells. In situ, the glands were also embedded in a matrix of fibroblasts (Figure 2A); some of these cells were associated with the isolated glands, and these fibroblasts also proliferated in culture media. Fetal sheep fibroblasts derived from skin were used as a control for fibroblasts and were positive for S100A4 (fibroblast stain), calponin, and ACTA2 and were nega- tive for epithelial-specific antigen (data not shown). All stains had negative controls where only the secondary antibody was used.

We also demonstrated that cells will grow as monolayers on the film of medium or as 3-dimensional structures. Under an inverted phase-contrast microscope, regions containing sweat gland epithelial cells were easily distinguishable from fibroblasts (Figure 3A). There were also 2 cell types present in the cell culture (Figure $3 \mathrm{~A}$ ), one which grew in a cobblestone paving
A

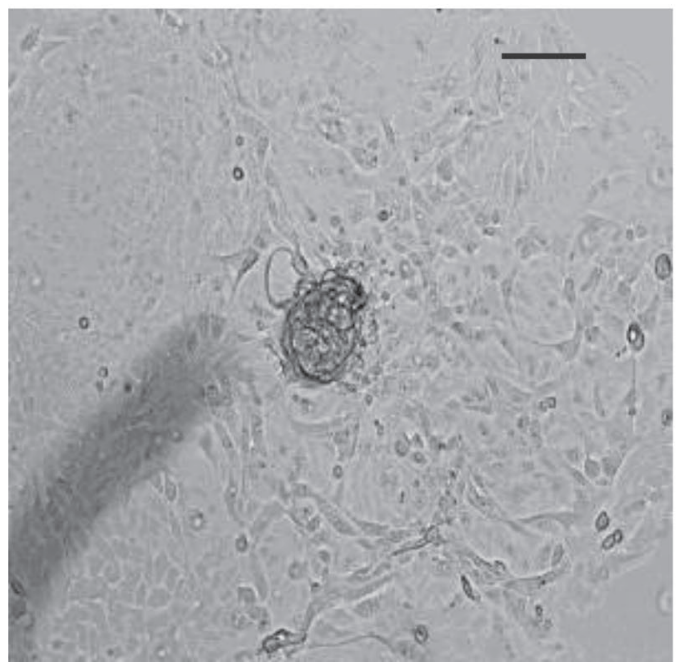

B

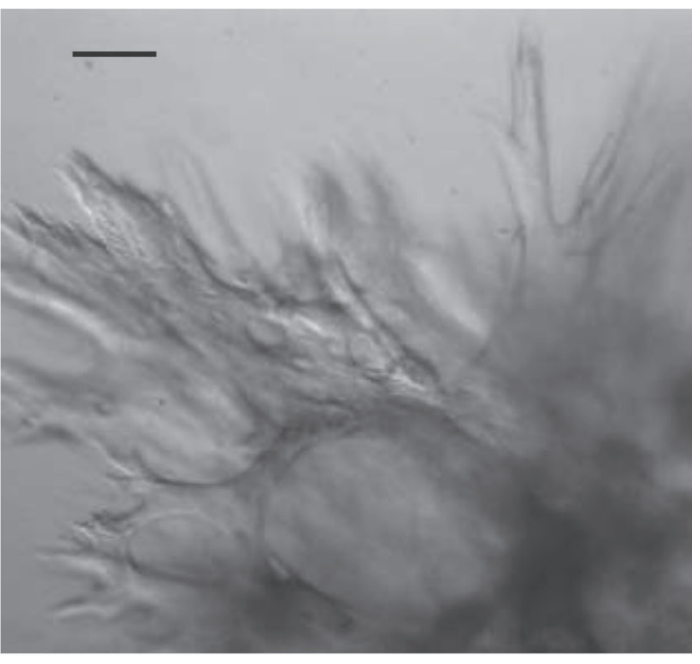

Figure 3. (A) Two-dimensional cell growth on plastic of apocrine sweat gland epithelial cells $12 \mathrm{~d}$ after isolation. (B) Three-dimensional growth after $29 \mathrm{~d}$ in a collagen gel matrix. Bar represents $10 \mu \mathrm{m}$. 
arrangement. They formed a monolayer that grew out from the sweat gland (Figure 3A), and the nuclei were round with oval or polygonal cell shapes. The second cell type in the cell culture had a spindle-shaped morphology with a spindle-shaped nucleus. Additionally, epithelial cells growing from isolated sweat glands in a collagen matrix grew in 3 dimensions and exhibited ductal branching (Figure 3B).

In primary culture, fibroblasts were usually mixed with epithelial cells, which may grow either in groups or scattered (Tao et al., 2010). As epithelial cells and fibroblasts have different tolerances to trypsin, this can be used to separate the 2 cell types. Research by Tao et al. (2010) and Lee et al. (1986) separated epithelial apocrine sweat gland cells from fibroblasts by adding trypsin, in which the fibroblasts detached first. The result was that only sweat gland epithelial cells remained. We supplemented the medium with different compounds to try to separate the cell types. Our complete medium was keratinocyte medium with $2.5 \%$ FBS, supplemented with antibiotics and $5 \mathrm{ng} /$ $\mathrm{mL}$ of $\mathrm{hEGF}$ and $0.05 \mathrm{mg} / \mathrm{mL}$ of $\mathrm{bPE}$, which resulted in both cell types growing in cell culture. We modified the Gomm et al. (1997) protocol to separate mammary epithelium from myoepithelium, and there was very little cell growth of either cell type.

\section{REFERENCES}

Bertipaglia, E. C. A., R. G. da Silva, V. Cardoso, and L. A. Fries. 2007. Hair coat characteristics and sweating rate of Braford cows in Brazil. Livest. Sci. 112:99-108.

Brayden, D. J., and J. Fitzpatrick. 1995. Cultural human sweat gland epithelia: Isolation of sweat glands using neutral red. Pharm. Res. 12:171-175.

Brody, S. 1945. Bioenergetics and Growth. Rheinhold, New York, NY.

Bullard, R. W., D. B. Dill, and M. K. Yousef. 1970. Responses of the burro to desert heat stress. J. Appl. Physiol. 29:159-167.

Cole, L., M. Anderson, P. B. Antin, and S. W. Limesand. 2009. One process for pancreatic $\beta$-cell coalescence into islets involves an epithelial-mesenchymal transition. J. Endocrinol. 203:19-31.

Collier, R. J.,, and K. G. Gebremedhin. 2015. Thermal biology of domestic animals. Annu. Rev. Anim. Biosci. 3:10.1-10.20.
Collier, R. J., C. M. Stiening, B. C. Pollard, M. J. VanBaale, L. H. Baumgard, and P. C. Gentry. 2006. Use of gene expression microarrays for evaluating environmental stress tolerance at the cellular level in cattle. J. Anim. Sci. 84:E1-E13.

Dikmen, S., E. Alava, E. Pontes, J. M. Fear, B. Y. Dikmen, T. A. Olson, and P. J. Hansen. 2008. Differences in thermoregulatory ability between slick-haired and wild-type lactating Holstein cows in response to acute heat stress. J. Dairy Sci. 91:3395-3402.

Finch, V. A. 1986. Body temperature in beef cattle: Its control and relevance to production in the tropics. J. Anim. Sci. 62:531-542.

Findlay, J. D. 1950. The effect of temperature, humidity, air movement and solar radiation on the behaviour and physiology of cattle and other farm animals. Bulletin no. 9. Hannah Dairy Research Institute, Kirkhill, UK.

Findlay, J. D., and S. H. Yang. 1950. The sweat glands of Ayrshire cattle. J. Agric. Sci. 40:126-133.

Freshney, I. 2010. Culture of Animal Cells: A Manual of Basic Technique and Specialized Applications. 6th ed. Wiley, Hoboken, NJ.

Gomm, J. J., R. C. Coope, P. J. Browne, and R. C. Coombes. 1997. Separated human breast epithelial and myoepithelial cells have different growth factor requirements in vitro but can reconstitute normal breast lobuloalveolar structure. J. Cell. Physiol. 171:11-19.

Hernandez, L. L., C. M. Stiening, J. B. Wheelock, L. H. Baumgard, A. M. Parkhurst, and R. J. Collier. 2008. Evaluation of serotonin as a feedback inhibitor of lactation in the bovine. J. Dairy Sci. 91:1834-1844.

Hongpaisan, J., A. L. Zhang, A. C. Mork, and G. M. Roomans. 1996. Use of primary cell cultures and intact isolated glandular epithelia for X-ray microanalysis. J. Microsc. 184:22-34.

Klungland, H., and D. I. Vage. 2003. Pigmentary switches in domestic animal species. Ann. N. Y. Acad. Sci. 994:331-338.

Lee, C. M., F. Carpenter, T. Coaker, and T. Kealey. 1986. The primary culture of epithelia from the secretory coil and collecting duct of normal human and cystic fibrotic eccrine sweat glands. J. Cell Sci. 83:103-118.

Lei, X., J. Wu, Y. Lu, and T. Zhu. 2008. Effects of acetylcholine chloride on intracellular calcium concentration of cultured sweat gland epithelial cells. Arch. Dermatol. Res. 300:335-341.

Mörk, A. C., J. Hongpaisan, and G. M. Roomans. 1995. Ion transport in primary cultures from human sweat gland coils studied with Xray microanalysis. Cell Biol. Int. 19:151-159.

Olson, T. A., C. Lucena, C. C. Chase, and A. C. Hammond. 2003. Evidence of a major gene influencing hair length and heat tolerance in Bos taurus cattle. J. Anim. Sci. 81:80-90.

Saga, K. 2002. Structure and function of human sweat glands studied with histochemistry and cytochemistry. Prog. Histochem. Cytochem. 37:323-386.

Tao, R., Y. Han, J. Chai, D. Li, and T. Sun. 2010. Isolation, culture, and verification of human sweat gland epithelial cells. Cytotechnology 62:489-495.

Yamane, J., and Y. Ono. 1936. Sweat glands of buffalo, zebu, Formosan and Dutch Friesian cattle. Mem. Fac. Sci. Agric. Taihoku. 19:85-136. 